\title{
Secondary School Students' Beliefs Towards Learning Physics and Its Influencing Factors
}

\author{
Abebe Adugna Chala *(Assistant Prof.) Ibrahim Kedir Shiferaw Wami \\ College of Natural and Computational Science, Department of Physics at Madda Walabu University, \\ P. O Box 247, Bale Robe Ethiopia
}

\begin{abstract}
Physics is considered as one of the most prevailing and problematic subject by the students in the natural science. Students believe physics as a difficult subject during high school and become more when they reach university. This paper deals with the students' beliefs about physics learning and relations with their practices based on contemporary literatures. Beliefs have generally been perceived through the personal experiences and interactions with immediate environment and setting. The objective of this article is to find out students' beliefs about physics learning and influencing factors and hence, has been reviewed systematically from over seventy different findings done. These beliefs are internally built in a person and can be difficult to alter. These lead us to perceive how students 'physics beliefs can shape their behaviors as to how they relate to learning physics. Student' beliefs toward physics are both positive and negative. Students who demonstrated positive beliefs tended to enjoy and learn effectively when they clearly understood physics well. Conversely, students with negative attitudes usually put less effort into their learning process. Most students disliked learning physics because it is believed to be difficult. Different factors have been examined from over hundred articles reviews that influence students' beliefs towards learning physics. These are the students' self-concept, self-efficacy and confidence contribute highly students' beliefs towards learning physics and intern affect for success or failure physics subject. Secondly teachers' personal experiences affect approaches to teaching; experience with schooling and instruction influences beliefs about children's learning and the role of teacher and formal knowledge in the context of pedagogical knowledge has been found to influence teacher beliefs. Teachers who do not provide support or show patience can have a negative impact on students' achievement. Studies have also shown that a positive correlation between a disadvantaged school environment and learners' beliefs towards physics at school. Cultural beliefs also influenced the scientific world in the most of the student's beliefs in creating misconceptions of students in describing, understanding, interpreting and predicting natural phenomena in physics classroom.
\end{abstract}

Keywords: students' belief, physics subject and secondary schools

DOI: $10.7176 /$ RHSS/10-7-05

Publication date: April $30^{\text {th }} 2020$

\section{Introduction}

Physics plays an important role in explaining the events that occur in the universe. In all events that around us can be found physical laws and principles. The developments in physics in the 20th century, it has been extremely successful in that it also greatly benefited to the other basic and applied sciences and many useful technologies to human life (Fishbein 1975). Although physics is in every area in our life and facilitate our lives, national and international studies show that success in physics education is lower than other disciplines (Gok and Silay 2008; Dieck 1997; Rivard and Straw 2000, Mattern and Schau, 2002). Secondary school physics is primarily concerned with the study of these two very important themes. In almost every aspect of life we encounter basic concepts of physics from biological cells and atoms to the universe. It is therefore, not possible to ignore the problems hinders students learning physics at the early stage special when they promote from elementary to secondary schools.

Young scientists particularly those in the rural areas, have ignored Physics in favor of Chemistry and Biology (Iraki 1994). Despite the importance of physics national development of a country, it is clear from research findings that the subject has been suffering from low benefaction and performance (Mankilik, 2005; Robert, 2000 and Kessel\& Hannover, 2004). The greatest worries which were raised by many researchers as research questions are; why are they shying away from this very important subject? What are the consequences of this trend? Is learning the subject is not enjoyable? Is it because of the students' belief that affects their performance level? A learner with a physics background is able to think both deductively and inductively and approach new situations with a high degree of precision and accuracy.

Despite the knowledge and application of physics is key role, it is plagued by persistent low enrolment and under-achievement by students. This has elicited a lot of concern and generated researches to establish the causes of repeated failures. Some of these had been ascribed to poor teaching methods, limited number of professionally trained teachers, lack of instructional facilities, unavailability of suitable practical equipment, inadequate funding among others (Simon, 2000; Stokking, 2000; Ogunniyi, 2009; Owolabi and Oginni, 2013; Bello, 2012). Attempts have been made by educational stakeholders to find ways of improving students' performance in the subject some of which have focused on identifying appropriate teaching methodology (Bello, 2011; Orora, Wachanga and 
Keraro, 2005, Kibett and Kathuri, 2005), improving on teachers' mastery of content and provision of instructional materials (Omosewo, 2009; Adeyemo, 2011; Akinfe, Olofinniyi and Fashiku, 2012). Despite all these efforts, the performance of students in Physics is still below expectation; it is therefore pertinent to consider other factors that could be responsible for under-achievement in the subject.

A major cause of under-achievement has been traced to the influence of misconceptions which students bring to science classroom especially Physics class (Samba, 2003; Ivowi, 2010). Research had shown that students' explanations of scientific phenomena are controlled by what they perceived from their cultural beliefs (Okebukola, 2002 and Yip, 2001).

In general different research results indicated students believed Physics as the most problematic area to learn within the realm of science, and it attracts fewer pupils than other natural science like chemistry and biology. The student success in physics is lower than chemistry and biology, that most of the students do not prefer the physics courses in their education life (Boylan, 1996; Mattern \& Schau, 2002; Rivard \& Straw, 2000). In science education literature, the most important reasons for the lack of success in physics have been suggested as little usage of Information and Communication Technologies (ICT) such as the presentation graphics in teaching physics and students' low attitudes towards physics (Craker, 2006; Normah and Salleh, 2006; Long, 1981; Newble, 1998).

Hence, Physics is believed as a difficult course for students from secondary school to university levels, and it is well known that both high school and college students find physics a difficult scientific discipline to succeed and avoid from it because of its negative reputation among students (Erdemir, 2009; Teo, 2008). In developed countries, it has been determined that goals of science are never fully realized, that student success in physics is lower than chemistry and biology, that students do not like science lectures and that most have no preference for physics (Boylan, 1996; Dieck, 1997; Mattern and Schau, 2002; Neathery, 1991; Rivard and Straw, 2000).

The declining interest to study physics on one hand and the lack of interest to take physics course in schools or avoiding physics and it is problem at national and international level. Very small number in enrollment and graduation rates in physics at all levels has been the case in many countries including the USA, UK, Germany, and the Netherlands (Tobias \&Birrer, 1999; Osborne, Simon, \& Collins, 2003). Existing research show that the erosion of beliefs and attitude in the subject found to emerge as early as lower at high school (Hoffmann, 2002) to later result in compromising university enrolment (Tobias \& Birrer, 1999).

In the researchers opinion therefore, beliefs and performance level in the subject could go together. This is because if a student is forced to take a course that he/she has negative attitude, it might be very difficult for the student to perform well. In view of the fore going, the researchers are of the opinion that when students' attitude towards physics is positive, performance in the subject will be optimal. Hence, it is very critical to examine students' background at secondary schools level by identifying gaps and to doing empirical research to this area which will be very helpful to young generation, to researchers, to all educational sectors and related, MoE of Ethiopia, government and nongovernment organization. As a result, it will be helpful for farther researches and to mitigate critically in education sectors. Hence, in this article students' Belief they experienced to learn physics in secondary schools has been presented.

\section{Students' Beliefs and Practice toward Learning Physics in Secondary Schools}

The most important conclusions from researches on factors related to achievement in schools are that (a) teachers are critical resources; (b) the composition of the student body matters; (c) schools make a difference, and (d) physical facilities, class size, curriculum, instructional strategies and other resources influence student learning indirectly through their effect on the behavior of teachers and students Hughes (1999).

These variables include learners' abilities, beliefs, attitudes and perceptions, family and socio-economic status, parent and peer influences, school related variables such as poor learning environment, learning cultures, past racial discrimination and low expectations by principals and teachers Singh et al. (2002). In this review factors that contribute in students, beliefs toward Physics, variables related learners and teachers have been reviewed.

\section{a. Definition of belief}

Personal beliefs must be inferred from an individual's words and actions (Pajares, 1992). It could be Formed early in life and reinforced by subsequent experiences, beliefs are intangible ideas and conceptions thought to be true (Richardson, 1996; Rokeach, 1986). Together with the attitudes they foster, they form belief systems with a nucleus of core beliefs (Rokeach, 1986). Belief systems are the driving force behind personal decisions and actions. Personal beliefs are firmly entrenched by the time a person reaches adulthood and do not easily change (Pajares, 1992; Rokeach, 1968). Although beliefs may be altered when newly acquired knowledge challenges what is believed to be true, long held core beliefs which are linked to personal experiences rarely change (Pajares, 1992).

\section{b. Learner Beliefs and Practice}

Learner belief are 'psychologically held understandings, premises, or propositions about the world that are felt to be true' Richardson (1996, in Peacock, 2001). While there are different understandings of learner beliefs, research studies do not really give a clear definition of learner beliefs about learning and they generally seek to identify learners' preconceived notions about what is involved in learning in order to predict expectation conflicts that may 
contribute to students' frustration, anxiety, lack of motivation, and in some cases ending foreign language study, and to help to facilitate the language learning and teaching process.

\section{c. Student beliefs and Expectations about physics}

Expectation of students about physics was used to represent students' prior conceptions, attitudes, beliefs, and assumptions about what sorts of things they will learn, what skills will be required, and what they will be expected to do in addition to their view of the nature of scientific information in a physics classroom as stated by Redish, Saul, and Steinberg, (1998). Students' expectations about their understanding of the process of learning physics and the structure of physics knowledge Redish et al. (1998). The term expectation was used in the same meaning in the present review.

Instructors in science courses may have implicit expectations about what students should learn and how to learn it Lin (1982). These goals as the "hidden curriculum" it has been shown that students come to physics classes with a variety of goals and expectations about physics and physics teaching Redish et al. (1998). As Hammer (1994) reports, some students consider physics as weakly connected pieces of information to be learned separately, whereas others see physics as a coherent set of ideas to be learned together. Some students perceive learning physics as memorizing formulas and problem solving algorithms, while others think that learning involves developing a deeper conceptual understanding. Some students believe that physics is not connected to the real world, while others believe that ideas learned in physics are relevant and useful in a wide variety of real contexts. These preconceptions may inhibit students' learning of the required material in their physics course (Mistades, 2007). Researchers who investigated students' beliefs and expectations and their role in physics learning have reported that students' expectations and beliefs have effects on how they study, how they learn, and what they want to learn (e.g., Hogan, 1999; Lederman, 1992; McDermott and Redish, 1999 and the references therein).

Many pre-college students have misconceptions both about science and about what they should be doing in a science class Carey et al. (1989) and Songer and Linn (1991). Other studies at the pre-college level determined some critical factors that comprise the relevant elements of a student's system of expectations and beliefs. students in middle schools and determined that they could categorize students as having beliefs about science that were either dynamic, science is understandable, interpretive, and integrated or static (science knowledge is memorization-intensive, fixed, and not relevant to their everyday lives Songer and Linn (1991). In describing high school students' assumptions about physics learning, Schoenfeld (1992) concluded that student's beliefs shape their behavior in ways that have extremely powerful (and often negative) consequences. Halloun and Hestene (1985) suggested that the more consistent the students' and instructors' views about learning physics were, the better these students performed in the course. Research on students' beliefs is important since they affect motivation (Hofer and Pintrich, 1997) and influence students' selection of learning strategies (Edmonson, 1989; Schommer, Crouse, and Rhodes, 1992). Beliefs are also found to be related to the ability to reason on applied tasks (Qian and Alvermann, 1995), how students solve physics problems (Hammer, 1994), conceptual learning gain in introductory physics courses (May and Etkina, 2002), and conceptual understanding (Songer and Linn, 1991) in middle school and university levels.

\section{d. Students Attitudes towards Physics}

Poor academic performance in Physics has been a concern in many high learning institutions in the last years around the world. Different authors attribute this poor performance to different causes, namely poor learning environment, poor teaching, inexperienced teachers, learning approaches, cognitive style of students, career interest, influence of parents and friends, low ability of the student, socio economic level and so on (Erdemir, 2009; e.g. Ibeh et al., 2013; Olusola \& Rotimini, 2012). But most of them agree on that the attitude of students toward Physics plays a big role in this poor performance. George (2006) defines the attitude toward science as the positive or negative feelings about science, specifically to science classes. The attitude of a student toward a learning subject has therefore an object of intensive research in the last years to determine its responsibility in poor performance in science in general and in physics in particular. Akinbobola (2009) introduced cooperative learning to boost students attitude toward Physics. She found that students taught using cooperative strategies show more positive attitude toward Physics compare to those taught with competitive and individualistic strategies. Marusic and Slisko (2012) opted for active learning to increase the students' attitude toward Physics. A positive shift of attitudes was observed in both groups of the experiment. In this research, we first investigated the attitude of Physics students at CST toward Physics, before suggesting some strategies to be used to improve this attitude and subsequently improve students' performance in Physics subjects.

Similarly, Negative attitude towards a certain subject makes learning difficult, while positive attitude stimulates students to do effort and leads to the high achievement in that subject (Veloo, Nor, \& Khalid, 2015). Relative to Physics, Godwin and Okoronka (2015) showed that a significant relationship exists between students ${ }^{\text {ee }}$ attitude and their corresponding academic performance in physics. Determining students ${ }^{\text {ee }}$ attitude towards a subject is therefore a useful task if one wishes to improve the performance of students in that subject. The estimation of studentse attitude towards natural sciences has been carried out by many researchers. In their researches, Wilson et al. (2000) and Kaya and Boyuk (2011)came to the conclusion that students ${ }^{\text {ee }}$ positive attitudes 
towards science highly correlate with their achievement in science. In the particular area of physics, because of a visible decline in the enrollment in physics and a fall in the interest in physics around the world, many researchers have been made to estimate the attitude of students towards physics at secondary schools and at universities. Many of them (Akinbobola, 2009; Alimen, 2009; Mekonnen, 2014) came to the same conclusion that the decrease in Physics academic achievement is alarming. The outstanding factor that caused this is the students ${ }^{\text {ee }}$ attitude towards Physics (George, 2000).

A plethora of research has being carried out in recent years concerning attitudes toward science/physics and the relationship between these attitudes and science achievement (Gungor et al, 2007; Papanastasiou \& Zembylas, 2002; Reid \& Skyabina, 2002). Several factors have been highlighted as main contributors to the negative attitudes that students possess towards the science subjects. These factors are related to school and science classes; the individual and even external factors relating to the status and rewards that different countries bestow onto physicsbased careers (Woolnough, 1994).

For the purpose of this paper, attitude is defined as the favourable or unfavourable response to things, places, people, events or ideas (Koballa, 1995). In Ireland, students' attitudes towards physics have declined increasingly over the last two decades with the popularity of Leaving Certificate Physics declining from 21\% to $15 \%$ since 1985 (Central Statistics Office). Students who decide to continue their studies in the field of physics are further hindered by the high drop-out rates within the discipline. Within the universities in the Republic of Ireland $22.2 \%$ fail to graduate in science courses, compared to $7.1 \%$ in the Law domain (Flanagan et al, 2001). Since only those students who take physics at senior level in secondary school and subsequently third level are eligible to pursue careers in the discipline, concerns have been raised about the nation's economic future.

To combat the negative attitudes towards physics and the enduring problem of high drop-out rates with physics courses new initiatives must be implemented into the classroom. Tinto, 2003 highlighted five conditions to help promote persistence within a course; expectations, support, feedback, involvement and learning. With the integration of these five conditions into the classroom the attainment of the students can be maximized. This paper highlights how the inclusion of Concept Mapping can offer the opportunity to integrate these five conditions into a physics classroom thus developing the students' knowledge and improve their attitudes towards physics.

\section{Factors impacting on Students' Beliefs}

From a review of the literature, there are four factors that play vitally impact on students' beliefs in learning physics. These include factors that associated with the students themselves, factors associated with the teachers, and factors associated with the school environment and culture. Each of the factors will be discussed in the following sections.

\subsection{Students Themselves on Students' Beliefs to Learn Physics}

The belief about self refers to student's self-concept and to their confidence and causal attributions in relation the subject Op't Eynde et al., 2002). According to McLeod (1994), it may include students' self-concept, self-efficacy and confidence for success or failure in the subject. The notion of students' beliefs about the self are categorized under two areas. These are academic self-concept beliefs and academic self-efficacy. These two beliefs will be discussed in the following sections.

\subsubsection{Academic self-concept beliefs}

Academic self-concept is an individual's perception of himself/herself Shavelson, Hubner, \& Stanton, (1976) in relation to academic setting. Moreover, it is how an individual thinks and feels about him/herself in relation to learning situations encountered Bong \& Skaalvik (2003)

Academic self-concept is important for students because it positively affects subsequent academic achievement and other educational outcomes, such as academic motivation, effort and grades (Marsh, Trautwein, Lüdtke, Köller, \& Baumert, 2005; Valentine, Dubois, \& Cooper, 2004). The more students take responsibility by putting much effort into their own learning, and remain persistent, the more likely they are to perform successfully (Fryer \& Elliot, 2012). Having a positive self-concept will determine students to perform better in their academic achievement. For instance, a self-concept statement: if I study hard, I will have better results.

According to Shavelson, Hubner, and Stanton (1976), belief about the self is formed through the individual's experiences with the environment and is influenced by environment reinforcements. For instance, students normally evaluate their high performance relative to their strong mathematical ability and the quality of their learning process (Zimmerman, 2000). Similarly, their academic self-concept tries to characterise such perceptions as having the cognitive abilities and competences in relation to good academic performance (Bong \& Skaalvik, 2003; Chmielewski, Dumont \& Trautwein, 2013; Haines \& Mueller, 2013).

One particular view of students' self-concept belief can be seen in the form of goal orientation belief. It focuses on reasons why students learn mathematics the way they do. Goal orientation beliefs suggest that students have their goals in learning mathematics (Op 't Eynde \& De Corte, 2006; Velayutham, Aldridge, \& Fraser, 2011). In Mapolelo's (2009) study he interviewed year-12 high school students to inquire if they were good at mathematics. Findings revealed that most students believed that they enjoyed the challenge and aimed to do better 
in their mathematics study. In addition students would desire the ability to work harder and to achieve success in mathematics (Mason \& Scrivani, 2004). Their goal in learning mathematics is to gain mathematical knowledge and understanding and to work to achieve better result in mathematics, which demonstrates by capability and cognitive skills (Schunk \& Richardson, 2011).

However, from negative experiences of learning, for example, some students believed they have poor mathematical ability and that their performance is far from other excellent students (Garcia, 2012). These students would often find mathematics to be a very difficult subject. Consequently, students with negative self-concept attribute their poor performances to lack of confidence, effort and ability, and to insufficient strategy (Zimmerman, 1998, as cited in Marchis, 2011) to successfully complete the task (Bandura, 1986). A student's negative selfconcept, for example, might be expressed as no matter how much time I spend doing mathematical tasks, I cannot get better result.

\subsubsection{Academic self-efficancy beliefs}

Self-efficacy is defined as one's capabilities to organize and execute the course of action required to produce a desired outcome Bandura (1983). Schunk and Pajares (2009) said that self-efficacy is a belief that emerges from thinking about what a person can learn or do; it is totally different from knowing what to do (as cited in Schunk \& Richardson, 2011). Self efficacy requires students to reflect on their skills and capabilities and to gain confidence to successfully accomplish a particular task (Bong \& Skaalvik, 2003; Zimmerman, 2000).

Self-efcacy is a dynamic aspect of the composition of other elements of the self-system, such as an individual's capacity, their success, their incentives and self-regulation mechanisms (Vardarl1, 2005). Gürcan (2005) defnes selfefcacy as the judgements individuals make by using their abilities, but not as a function of their abilities. Self-efficacy contributes to students' success, because it affects their behaviour when asking for academic help and their use of learning strategies. Self-efcacy has a bearing on many things, such as academic success, social abilities, stopping smoking, athletic success, career choice, assertiveness, surviving a heart attack and dealing with feared events, among others (Açıkgöz, 2000). Research carried out in this area shows that students who have high levels of academic selfefcacy are more willing to work in challenging areas of study and show more of an effort in them. They are better at overcoming obstacles, have higher targets and are more confident, and as a result their academic success is higher (Gülten \& Soytürk, 2013). A student with higher levels of self-efcacy on physics learning actively participates in the lecture, allocates time for studying physics subjects and develops various learning strategies (İsrael, 2007). Thereby, the most important factor influencing academic success in physics is the level of self-efcacy. It is crucial to take this into consideration when organizing teaching activities for students, in order for them to achieve better learning outcomes (Dowd et al., 2015). Besides, there are studies showing selfefcacy perception towards physics lecture as an indicator of academic achievement of the students (Capri et al., 2012; Karakoyun \& Kavak, 2008).

Since Bandura (1977) explained the self-efcacy concept in the 1970s, there have been a lot of studies referenced in literature about developing self-efcacy scales and showing the importance of students' academic self-efcacy (Woo, 1999; Ekici, 2009; Ekici, 2012). Önen and Kaygisız (2013) identifed the levels of self-efcacy of science teacher candidates regarding science education, and determined that they were generally "good". In their research, Selçuk et al. (2008) analysed the change in students' self-efcacy regarding physics related to gender, and found that there was a meaningful difference in favour of male students. Shaw (2004) investigated the relationship between gender and students' self-efcacy and success for those studying physics at college and university level. Shaw determined that there was a signifcant difference between self-efcacy scores according to the gender of students, with female students having lower average scores. Mujtaba and Reiss (2014) investigated the factors that influence 15-year-old students' intentions to study physics post-16, when it is no longer compulsory. The result of the study indicated that extrinsic motivation in physics was the most important factor associated with intended participation. Maskan (2010) identifed the self-efcacy levels of teacher candidates, who were still partaking in the physics teacher training programme, and determined that the mean of the self-efcacy score of the ffth grade students was higher than that of the frst grade students. In their research, Yener et al. (2012) worked with student science teachers and analysed the effect of the use of animation and simulation in physics laboratories on students' self-efcacy. It was determined that when used solely in a laboratory, animation and simulation based learning methods do not change students' self-efcacy in a meaningful way. In their research which examined if taking the course of "Didactic Physics" increase the self-efcacy perception levels of prospective classroom teachers, Juuti, Lavonen and Meisalo (2005) concluded that there is a signifcant relationship between gender and this course with a minor effect on self-efcacy related with physics. There have been numerous papers and research done on student self-efcacy and its place in the classroom (Aloe, et al., 2014; Tanel, 2013; McKinnon \& Lamberts, 2013; Arslan, 2013; Louis \& Mistele, 2012; Velayutham, Aldridge, \& Fraser, 2012)

\subsection{Influence of Teachers' Beliefs on Students' to learn Physics}

Teachers' beliefs as being derived from three main sources Richardson (1996). Firstly, personal experiences of individual teachers have been shown to affect approaches to teaching, in particular experiences of community 
(Clandinin\& Connelly, 1991, cited in Richardson) and of parenting (Bullough\& Knowles, 1991, cited in Richardson). Secondly, experience with schooling and instruction influences beliefs about children's learning and the role of teacher (Britzman, 1991, cited in Richardson), and are considered to be more powerful influences on beliefs than experiences afforded by teacher education courses (Brousseau, Book, \& Byers, 1988; Feiman-Nemser, 1983; Lortie, 1975, cited in Richardson). Lastly, formal knowledge in the context of pedagogical knowledge, although not as powerful as other factors, has been found to influence teacher beliefs (Clift, 1987; Grossman, 1990, cited in Richardson).

Teachers' practices were influenced by a network of beliefs they held about language, beginning language learning, and learners Burns (1992, as cited in Borg, 1999). Also Burns (as reported in Borg, 1999) noted that teachers' practices were shaped by beliefs relating to the institutional culture of the school they worked in, their own personal beliefs about language, learners, and learning, and their beliefs about specific instructional tasks and materials.

A recent research on teachers' beliefs explores a significant positive relationship among teachers' beliefs, practices and students' problem solving achievement (Polly et al., 2013). Classroom activities of teachers are guided by their prejudiced assumptions. They do not simply perform as robot. Being a human being, they have their own feelings, emotions and passions about their environments. These attributes appear in their classroom instructional practices. For enhancing the quality of physics teaching and learning, we should understand the ideas held by the teachers and how these ideas or beliefs have reflected in their instructional practices (Boz, 2008).

Teachers' beliefs can be classified into expressed, entrenched and manifested beliefs (Keys, 2003). Entrenched and manifested beliefs are the beliefs that strongly influenced teachers' practice whereas expressed beliefs are espoused and rarely appear in practice (Keys, 2003). Teachers may change their expressed beliefs to entrenched beliefs by participating in professional development programs (Sheffield, 2004).

The following types of beliefs affect activities in classrooms and need to be examined in a model of teaching and teacher professional learning: beliefs about the nature of subject matter (in general and with regard to the specific topic being taught); beliefs about the nature of the learning process (both cognitive and affective); beliefs about the nature of the teaching process and the role of various kinds of instructions; beliefs about particular students and classes of students (Schoenfeld, 1997)

Bryan (1998) classified teachers' beliefs about science teaching and learning into six categories, which include beliefs about: the value of science and science teaching; the nature of scientific knowledge and goals of science instruction; control in the science classroom; how students learn science; the students' role; and the teachers' role.

\subsection{Influence of School-Related Issues on Students' Belief to Learn Physics}

Several studies have shown a positive correlation between a disadvantaged school environment and learners' achievement at school. For example learners in the Western and Northern Cape provinces, which have large white populations and well-endowed communities and schools, lead in pass rates in grade twelve examinations whereas those in Limpopo Province with its black population majority rank last in this regard (Murray, 1997). Attwood (2001) also found that grade eight learners in schools situated in economically depressed areas of the Cape Flats have a lower physics achievement than those who come from families with high socio-economic status. Furthermore, a comprehensive study on the status of mathematics and science teachers in South Africa found that black learners were underprovided for and performed worse than their white peer group in these subjects Arnott et al., (1997).

\subsubsection{Learning environment}

According to Smith and Ragan (1993) a learning environment comprises teacher, existing curriculum, instructional equipment as well as the institutional and larger learner community. In this regard Shields (1991) stated that the school environment is the broader climate or context of the school that either facilitates or constrains classroom instruction and learning. Ross, Farish and Plukett as cited in Zaaiman (1998) describe the learning environment that is considered disadvantageous for Australian schools by using detailed census-based social profiles of school catchment areas. A learning environment, particularly the school, was considered as disadvantaged if a high proportion (of the enrolment) of learners came from neighborhoods having certain characteristics known to be associated with a low capacity to take advantage of educational facilities. These characteristics include, among others, a high percentage of persons in low status jobs with low income or with lack of formal educational qualifications. Furthermore, many families with single parents and more non-fluent English speakers (English as a second language) were found in the low socio -economic areas. The homes of the disadvantaged tend to be more crowded, lacking in magazines, newspapers, and other objects that are likely to help in the development of the learner. Parents of the disadvantaged learner give little language encouragement to their children, have less direct interaction with them and take less interest in their learning.

\subsubsection{Curriculum}

According to Pinar, Reynolds, Slattery and Taubman (1995) the concept of curriculum is highly symbolic; it is 
what the older generation chooses to tell the younger generation. Beggs (1995) states that curriculum traditionally means a list of content topics in a national or school syllabus and examination prescription, generally referred to as course outline. According to Beggs (1995: 97-106) a physics curriculum includes: Mathematical content (what mathematicians know) Mathematical processes (what mathematicians do) Mathematical thinking and logical reasoning, problem-solving making connections and using computational tools

\subsubsection{School and class size}

School size and class size have been shown to have an impact on achievement. Lee, Smith and Croninger (1997) observed that larger schools had a negative influence on academic achievement in high school mathematics and science. In contrast, Rutter (1983) found no relationship between the size of the school and scholastic achievement; effective schools can be very small, very large or somewhat in-between. Rutter (1983) further observed that the relationship between the class size and a learner's achievement is not well defined for classes with 20 to 40 learners. Class sizes of below 20 learners have been found to be advantageous for disadvantaged learners. In this respect Rutter (1983) argued that small school size facilitates social interaction and inhabits teacher specialisation.

\subsubsection{Effectiveness of schools}

Effective school characteristics are what help to create a fertile school culture that facilitates learners' achievement. Several researchers (Henson \& Eller, 1999; Berliner, 1990, and Rutter, 1983) have identified such characteristics. Their findings indicate that learners excel when the following factors are present (Henson \& Eller, 1999; Berliner, 1990, and Rutter, 1983): Strong leadership is provided by a principal who works with the staff to communicate the mission of the school; provide reliable support for staff; and meet with teachers and other members of the staff frequently to discuss classroom practices. High learner achievement is the foremost priority of the school, and the school is organized around this goal as shown by teachers who demonstrate high expectations for learners' achievement and make learners aware of and understand these expectations. Parents are aware of, understand, and support the basic objective of the school and believe they have an important role to play in their children' education. Teachers work together to provide an orderly and safe school environment. Schools use evaluation to measure learners' progress and promote learning

\subsection{Influence of Cultural Belief on Students' to learn Physics}

Learning is known to be culture dependent (Mwamwenda, 1996). It has been very difficult to explain most natural occurrences and issues in African life using scientific knowledge; this is because most of the people's beliefs have been crowded with mythology and superstitions Okoye and Okeke (2007). It is mostly based on power of witchcraft and evil spirits which is a departure from scientific explanations. This has resulted to divergence between students' daily experience in the classroom and the scientific world with most of the students having significant difficulties in describing, understanding, interpreting and predicting natural phenomena (Driver et. al., 1994, Engelhardt et al, 2004, Osborne and Freyberg, 1985).

Science educators are now conscious of the need to relate science more closely to the students' cultural environment in order to minimize the possible conflicts that might arise from their view of the world and that of science. This could be done by carefully considering the traditional point of view that has appropriate relation to scientific concepts. Ausubel (2000) have argued that the construction of new knowledge in science is strongly influenced by prior knowledge that is conceptions gained prior to the new learning. Since Physics is an important science subject taught in secondary schools which relates with physical phenomena and how they are connected to man's daily lives, there is therefore the likelihood of cultural beliefs exerting influence on learning and manipulation of concepts. It is therefore pertinent that Physics teachers assist their students to use their knowledge in ways that draw on their cultural experiences for meaningful learning to take place. This study therefore aimed at investigating the influence of cultural believes and practice on secondary school students' understanding of atmospheric-related Physics concepts.

A major cause of under-achievement has been traced to the influence of misconceptions which students bring to science classroom especially Physics class (Samba, 2003; Ivowi, 2010). Research had shown that students' explanations of scientific phenomena are controlled by what they perceived from their cultural beliefs (Okebukola, 2002 and Yip, 2001). This is an indication that students come to Physics class with the cultural misconception believe that they hold, this is in consonant with Ododo (2014) who opined that students bring many of their cultural practices that they have heard or held into Biology classes.

Furthermore, the studies found that the majority of the students believed that these cultural concepts are true. Some of them even believed that they are doctrinal issues, stories, cultural, religious, believe of the forefathers and philosophical. According to Yip (2001), personal experience and opinion are related to cultural factors prevalent in the society. This is because cultural situation at home give room for conflicting traditional beliefs and superstitions which cause misconceptions that lead to underachievement in the related subject where misconceptions are held. In addition, Samba (2003) found that students cannot learn new concepts if alternative models that gives explanation about a phenomenon exist in their mind except a platform is made available to them to confront their misconceptions, reconstruct and internalize their knowledge. 
Also, result from research question three which aimed at finding the students' sources of information about the cultural concepts revealed the sources of information to be majorly from their grandparents, parents, story books and friends. Few of them have their sources to be from academic journals and library. Others sources were found to be from television, radio, newspaper, internet, school and friends.

In addition, the findings from research question four which sought to find the influence of cultural beliefs on students' academic performance in Physics revealed that most of the students scored below average. This showed that there was significance influence of the belief of students in cultural concepts on their academic performance in Physics with many of them performing below average. This is an indication that the misconceptions held by students have negative influence on their academic performance in Physics. This is so because Okebukola (2002) opined that learners who have had themselves established in their cultural belief are likely to find the study of science mystifying because of the likely conflict between their anthropomorphic view of their world and the mechanistic views presented in science. Also, Okoye \& Okeke, (2007) and Igbokwe (2010) also found that the cultural environment in which science is taught significantly affects its learning. This implies that misconceptions from cultural believe brought into Physics class by students significantly affect their learning of Physics.

It can be concluded that Physics students hold cultural believes and ideas which they heard mainly from their parents. It was further that they bring their cultural believes into Physics class which can lead to misconceptions in understanding Physics concepts. Also, the misconceptions held by students due to their cultural believe significantly influence their academic performance in Physics negatively. It is therefore recommended that workshops, seminars and refresher courses be organized for Physics teachers on how to correct identified misconceptions. This will enhance scientific worth like significant mindedness and understanding of Physics concepts. Identified cultural beliefs and related misconceptions can be used by Physics textbooks authors to illustrate Physics concepts so as to sufficiently explain them and significantly advance learning.

\subsection{Gender difference}

Gender differences in interest emerge when other factors come into play which can compromise self-concept of performance in physics. The gender difference in interest seems to be sufficiently explained by the gender differences of other variables, especially by differences in self-concept Hoffman (2002). In a similar study, Ziegler, Broome, and Heller (1999) found out that interest and achievement in physics are also affected by parental cognition and gender stereotypic beliefs among boy and girls. The bourgeoning body of literature regarding the pattern of major choice as a function of gender shows a consistent pattern. For instance, an earlier study by Boli, Steinkemp, and Maehr (1984, cited in Ethington, 1988) found out that men "es achievement and attitude towards science to be higher than women while at the same time noting a discernable pattern of differences between the sexes in motivational orientation in particular areas of science. Accordingly, females are inclined more to life sciences while males are oriented towards physical sciences. Nonetheless, Boli, Allen, and Payne (1985) indicated that women choosing quantitative fields were likely to major in physics and Engineering.

Further, there is evidence to suggest that intervention through curriculum innovation that addresses the interest and experiences of females positively impacted girlse motivation, achievement and interest in physics (Hannover, 1991). However, Hoffmann (2002) found that interest and motivation to study physics declined with increase in grade level for both sexes. Other studies which applied innovative curriculum that considered female interest and employed constructivist teaching methodology came out with conflicting results. In this connection, unlike Lawrenz et al. (2009) and Lorenzo et al. (2006), a similar study on a relatively larger sample failed to yield consistent results. Lawernz et al. (2009) further claim that males and females have significantly different prior understandings of physics and mathematics with females less likely to take high school physics and making more negative shifts in attitude towards physics. The interest and attitude of boys and girls towards physics as school subject (Hannover, 1991; Hoffmann, 2002; Häusler \& Hoffmann, 2002) and the effect of parental influence and stereotypic beliefs (e.g., Zeigler et al., 1999). A related study in Ethiopian context also showed a pattern of parental influence towards gender-consistent choice of career or field of study (Semela, 2008).

\section{Summary}

Beliefs are mental constructs that play a very important role in shaping each individual's performances. Factors such as the student themselves, teachers, school environment and culture play major roles that impact on students' beliefs and attitudes in both positive and negative ways. Science teachers' hold beliefs about the value of science and science teaching, the nature of scientific knowledge and goals for teaching science, control in the science classroom, how students learn science, students' role, and teachers' role. Teachers' beliefs may be entrenched or manifested beliefs that strongly influence their practice, or expressed beliefs that rarely appear in practice. Classroom environment is another aspect that influences the quality and effectiveness of students' learning. Both the psychosocial and the physical aspects of classroom environment influence students' opportunity for learning and ultimately their attitudes to physics and physics achievement. The students' beliefs about the nature of physic in terms of physics content referred to aspect of number, calculations, formulas and topics. 
Students' beliefs about the physics processes revolved around the ideas of problem solving using procedures and steps. Moreover, beliefs of the nature of physics in terms of cognitive processes aligned to general thinking and learning. Students' beliefs and attitudes towards the utility of physics were positive in that students used physics ideas learnt in school and made connections to practical situations in their everyday life. Students and teachers are seen as very crucial factors in affecting students' beliefs toward learning physics and intern affects achievement. In terms of gender differences more boys than girls hold more positive beliefs and attitudes.

\section{Reference}

Açıkgöz, K. Ü. (2000). Effective learning and teaching (3Ed.). İzmir: Kanyılmaz Printing.

Adeyemo, S. A. (2011). The effect of teachers' perception and students' perception of Physics classroom learning environment on their academic achievement in senior secondary schools Physics. International Journal of Educational Research and Technology, 3 (1), 74-81.

Akinbobola, A. O. (2009). Enhancing Studentse Attitude Towards Nigerian Senior Secondary School Physics Trough the Use of Cooperative, Competitive and Individualistic Learning Strategies. Australian Journal of Teacher Education, 34(1), 1-9.

Akinfe, E., Olofinniyi, O.E., \& Fashiku, C. O. (2012). Teachers' Quality as Correlates of Students' Academic Performance in Biology in Senior Secondary Schools in Ondo State, Nigeria. Online Journal of Education Research. Volume 1, Issue 6.

Alimen, R. A. (2009). Attitude Towards Physics and Physics Performance, Theories of Learning, and Prospects in Teaching Physics. Liceo Journal of Higher Education Research, 6(1), 301-320.

Aloe, M. A., Amo, L. C., \& Shanahan, M. E. (2014). Classroom management self-efficacy and burnout: A multivariate metaanalysis. Educational Psychology Review, 26 (1), 101-126.

Arslan, A. (2013). Investigation of relationship between sources of self-efficacy beliefs of secondary school students and some variables. Educational Sciences: Theory and Practice, 13 (4), 1983-1993.

Ausubel, D. P. (2000). The Acquisition and retention of knowledge. The Netherlands: Kluwer Academic Publishers. Accessed 12 May 2010.

Bandura, A. (1977). Self-efcacy: Toward a unifying theory of behavioural change. Psychological Review, 84 (2), 191-215.

Bandura, A. (1997). Self-efficacy: The exercise of control. New York: Freeman.

Bandura, A. (1986). Social foundation of thought and action: A social

Bello, T. O. (2012). Effect of availability and utilization of Physics laboratory equipment on students' academic achievement in senior secondary school. World Journal of Education, Vol.2 (5), 1-7.

Bello, T.O. (2011). Effect of group instructional strategy on students' performance in selected Physics concepts. The African Symposium, 11 (1), 71-79.

Bong, M., \& Skaalvik, E. (2003). Academic self-concept and self-efficacy: How different are they really? Educational Psychology Review, 15(1), 1-40.

Çapri, B., \& Çelikkaleli, Ö. (2012). Analysis of prospective teachers' attitudes and professional efcacy beliefs towards teaching

Boz, N. (2008).Turkish pre-service mathematics teachers' beliefs about mathematics teaching.Australian Journal of Teacher Education, 33 (5), 66-80.

Çalışkan, S., Sezgin, Selçuk, G., \& Özcan, Ö. (2010). Self-efcacy beliefs of prospective physics teachers: effects of gender, class level and academic success. Kastamonu Journal of Education, 18 (2), 449-466.

Chmielewski, A. K., Dumont, H., \& Trautwein, U. (2013). Tracking effects depend on tracking type: An international comparison of students' mathematics self-concept. American Educational Research Journal, 50(5), 925-957.

Dieck, A. P. (1997). An effect of a newsletter on children's interest in an attitude toward science, Arizona State University.

Dowd, J. E., Araujo, I., \& Mazur, E. (2015). Making sense of confusion: Relating performance, confdence, and self-efcacy to expressions of confusion in an introductory physics class. Physical Review Special TopicsPhysics Education Research, 11 (1), 010107.

Driver, R., Squires, A., Rushworth, P., and Wood-Robinson, V. (1994). Making Sense of Secondary Science. London, Routledge

Ekici, G. (2009). Adaptation of the biology self-efcacy scale to Turkish. Kastamonu Journal of Education, 17 (1), $111-124$

Ekici, G. (2012). Academic self-efcacy scale: The study of adaptation to Turkish, validity and reliability. Hacettepe University Journal of Faculty of Education, 43,174-185.

Engelhardt, P.V., Corpuz, EG, Ozimek, D. J. \& Rebello, N.S. (2004). The Teaching Experiment: What it is, and what it isn't. 2003 Physics Education Research Conference 720, 157-160

Erdemir, N. (2009). Determining students ${ }^{e e}$ attitude towards physics through problem-solving strategy. Asia- 
Pacific Forum on Science Learning and Teaching, 10(2), 1-19.

Ethington, C. A. (1988). Differences among women intending to major in quantitative fields of study. Journal of Educational Research, 81, 354-359.

Fenci, H., \& Scheel, K. (2005). Engaging students: An examination of the effects of teaching strategies on selfefcacy and course climate in a non-major physics course. Journal of College Science Teaching, 35, 1.

Fishbein, M. \&Ajzen, I. (1975). Belief, attitude, intention, and behavior: an introduction to theory and research. Reading. MA: Addison-Wesley.

Fraser, B. (2012). Classroom learning environments: Retrospect, context and prospect. In B. J.

Fraser, B. J. (1986). Classroom environment. London: Croom Helm.

Fraser, K. Tobin, \& C. J. McRobbie (Eds.), Second International Handbook of Science Education (Vol. 24, pp. 1191-1239). Dordrecht, NL.

Garcia, G. C. (2012). Students' beliefs toward mathematics as related to their performance in college algebra. JPAIR: Multidisciplinary Research, 9(1), 93-105.

George, R. (2006). Measuring change in Students ${ }^{\text {ee }}$ Attitude toward Science over Time: An Application of Latent Variable Growth Modeling. Journal of Science Education and Technology, 9(3), 213-225.

Godwin, B. A., \& Okoronka, U. A. (2015). Attitude and Academic Performance of Senior Secondary School Students in Physics in Nigeria.

Gok, T. \&Silay, I. (2008). The effects of problem-solving strategies teaching on problem solving attitude, in the cooperative learning groups in physics education.Journal of Theory and Practice in Education, 4 (2), 253-266

Gülten, D. Ç., \& Soytürk, İ. (2013). The relationship between the academic success point average and geometry self-efcacy of 6thgrade elementary school students. Mehmet Akif Ersoy University Journal of Faculty of Education, 25, 55-70.

Gungor, A., Eryilmaz, A. and Fakioulu, T. (2007). The Relationship of Freshmen's Physics Achievement and their Related Affective Characteristics, Journal of Research in Science Teaching, 44(8), 1036-1056.

Gürcan, A. (2005). The relationship between computer self-sufciency perception and cognitive learning strategies. Eurasian Journal Educational Research, 5 (1), 179-193.

Hannover, B. (1991). Zur unterrepräsentanz von mädchen in naturwissenschaften und technik: Psychologische Prädiktoren der fach- und berufswahl. Zeitschrift für Pädagogische Psychologie, 5(3), 169-186.

Hannover, B., \& Kassels, U. (2002). Monoedukativer anfangsunterricht in physik in der gesamtschule. Zeitschrift für Entwicklungspsychologie, 34(4), 201-215.

Hofer, B. K., \&Pintrich, P. R. (1997). The development of epistemological theories: Beliefs about knowledge and knowing and their relation to learning. Review of Educational Research, 67(1), 88-140.

Hoffmann, L. (2002). Promoting girlse interest and achievement in physics classes for beginners. Learning and Instruction, 12, 447-465.

Ibeh, G. F., Onah, D. U., Umahi, A. E., Ugwuonah, F. C., Nnachi, N. O., \& Ekpe, J. E. (2013). Strategies to Improve Attitude of Secondary School Students towards Physics for Sustainable Technological Development in Abakaliki L.G.A, Ebonyi-Nigeria. Journal of Sustainable Development Studies, 3(2), 127-135.

Igbokwe, C. O. (2010). The effect of multicultural learning environment on cognitive achievement of pupils in primary science. Journal of Science Teachers' Association of Nigeria (STAN); 45 (1\&2): 9-19.

Iraki, N.W., (1994) Students and teachers' expectations of practical work in physics. A study of Laikipia and Nyandarua Districts of Kenya

Israel, E. (2007). Self regulation instruction, science achievement and self-efcacy. Doctoral Thesis, Dokuz Eylül University, Institute of Educational Sciences, İzmir.

Ivowi, U.M.O. (2010). Misconceptions in Science. Lagos: Foremost Educational Services Ltd

Juuti, K., Lavonen, J., \& Meisalo, V. (2005). Enhancing primary school student teachers' perceived physics related self-efcacy. 30th Annual Conference ATEE, 22-26 October, Amsterdam, 2005.

Karagöz, Y., \& Kösterelioğlu, İ. (2008). Development of the evaluating scale of communication skills through the method of factor analysis. Dumlupinar University Journal of Social Sciences, 21, 81-98.

Karakoyun, F., \& Kavak, M. T. (2008). Advantage of web survey and the application of web survey to the physics attitude scale as an example of practice. Dicle University Journal of Ziya Gökalp Faculty of Education, 11, $129-141$

Kaya, H., \& Boyuk, U. (2011). Attitude towards physics lessons and physical experiment of the high school students. European Journal of Physics Education, 2(1), 38-49.

Keys, M. P. (2003). Primary and Secondary Teachers Shaping the Science Curriculum: The Influence of Teacher Knowledge. Queensland University of Technology.

Kibett, J.K. \& Kathuri, N.J. (2005). Effects of projected-based learning on students' performance in secondary school Agriculture. Zimbabwe Journal of Educational Research, 17 (1), 30-38.

Koballa, T.R. (1995). Children's Attitudes Toward Learning Science, in Glynn, S. and Duit, R. (eds.) Learning Science in the Schools: Research Reforming Practice Mahwah, NJ: Erlbaum. 
Kurbanoğlu, N. İ., \& Takunyac1, M. (2012). An investigation of the attitudes, anxieties and self-efcacy beliefs of high school students towards mathematics lessons in terms of some variables. International Journal of Human Sciences, 9 (1), 110-130.

Lawrenz, F., Wood, N. B., Krichoff, A., Kim, N. K., \& Eisenkraft, A. (2009). Variables affecting physics achievement. Journal of Research in Science Teaching, 46(9), 961-976.

Louis, R. A., \& Mistele, J. M. (2012). The differences in scores and self-efficacyby student gender in mathematics and science. International Journal of Science and Mathematics Education, 10, 1163-1190.

Mankilik, M. (2005). How to answer physics theory examination questions in West African Examination Council and National Examinatiom council. Universdity of Jos, journal of education studies, 11 (1), 77-81.

Mansor, R., Halim, L., \& Osman, K. (2010). Teachers' knowledge that promotes students ' conceptual understanding. World Conference on Learning, Teaching and Administration Papers, 9, 1835-1839.

Mapolelo, D. C. (2009). Students` experiences with mathematics teaching and learning: listening to unheard voices. International Journal of Mathematical Education in Science and Technology, 40(3), 309-322.

Marchis, I. (2011). Factors that influence secondary school students' attitude to mathematics. The 2nd International Conference on Education and Educational Psychology 2011, 29(0), 786-793.

Markula, P., \& Silk, M. (2011). Paradigmatic approaches to physical culture. London, England: Palgrave Macmillan.

Marsh, H. W., Trautwein, U., Lüdtke, O., Köller, O., \& Baumert, J. (2005). Academic self-concept, interest, grades, and standardized test scores: Reciprocal effects models of causal ordering. Child Development, 76(2), 397416.

Maskan, A. (2010). Assessment of the self-efcacy beliefs of prospective physics and mathematics teachers towards physics. Uludă University Journal of Faculty of Education, 23 (1), 31-42.

Mason, L., \& Scrivani, L. (2004). Enhancing students' mathematical beliefs: an intervention study. Learning and Instruction, 14(2), 153-176.

Mattern, N. \&Schau, C. (2002).Gender difference in attitude-achievement relationships over time among white middle-school students.Journal of Research in Science Teaching, 39, (4), 324-340.

McKinnon, M., \& Lamberts, R. (2013). Influencing science teaching self-efcacy beliefs of primary school teachers: A longitudinal case study. International Journal of Science Education, Part B: Communication and Public Engagement, 4 (2), 172-194.

McLeod, D. B. (1994). Research on affect and mathematics learning in the JRME: 1970 to the present. Journal for Research in Mathematics Education, 25(6), 637-647.

McMillan, J. H. (2012). Educational research: Fundamental for the consumer (6th ed.). Boston, MA: Pearson.

Mekonnen, S. (2014). Problems Challenging the Academic Performance of Physics Students in Higher Governmental Institutions in the Case of Arbaminch, Wolayita Sodo, Hawassa and Dilla Universities. Natural Science, 6, 362-375.

Morakinwa, I. (2003). Poor academic performance in science, in technical college of education.Causes and implications. Ibadan, Nigeria.

Mujtaba, T., \& Reiss, M. J. (2014). A survey of psychological, motivational, family and perceptions of physics education factors that explain 15-year-old students' aspirations to study physics inpost-compulsory English schools. International Journal of Science and Mathematics Education, 12 (2), 371-393.

Mwamwenda, T. S. (1996). Educational Psychology. An African Perspective. Natal: Pietemaritzburg, Butterworth Publishers, 107-145.

Nathan, S.And Brian, L. (1995). Physics laboratory Manual: A students' physics practical guide. European journal of science education, 5 203-15.

Nderitu, M.K., (2007) Determinants of enrolment and performance in physics in selected secondary schools in Murang'a District, Kenya.

Nzewi, A. W. (2003). Predicting academic performance in college. New York: The free press

Ododo, O. M. (2014). Influence of Cultural Practice-Related Misconceptions on Achievement of Senior Secondary Biology Students in Zone C of Benue State, Nigeria. British Journal of Education, Society \& Behavioural Science, 4(12), 1703-1715

Ogunniyi, M. B. (2009). Science, Technology and Mathematics. International Journal of Science Education, 18 (3), 267-284

Okebukola, P. (2002). Beyond the stereotype to new trajectories in science teaching. Ibadan: Science Teachers Association of Nigeria.

Okoronka, A. U. \&Wada,Z. B. (2014). Effect of Analogy Instructional Strategy, Cognitive Style and Gender on Senior Secondary School Students Achievement in Some Physics Concepts in Mubi Metropolis, Nigeria.

Okoye, B. E. \& Okeke, O. C. (2007). Efficacy of eliminating superstitious beliefs strategy on achievement and knowledge retention in genetics among secondary school students. Journal of Science Teachers

Olusola, O. O., \& Rotimini, C. O. (2012). Attitudes of students towards the study of Physics in College of 
Education Ikere Ekiti, Ekiti State, Nigeria. American International Journal of Contemporary Research, 2(12), 86-89.

Omosewo, E.O. (2009).Views of Physics teachers on the need to train and retrain Physics teachers in Nigeria. African Research Review, 3 (1), 314-325.

Onah D. U. and Ugwu E. I. (2010).Factors which predict performance in secondary school physics in Ebonyi north educational zone of Ebonyi State, Nigeria. Advances in Applied Science Research, 1 (3): 255-258.

Önen, F., \& Kaygisız, G. M. (2013). The self-efcacy beliefs of prospective science teachers towards science education between 6 and 8 semesters and their opinions related to this belief. Educational Sciences: Theory and Practice, 13 (4), 2449-2453.

Orora, W.,Wachanga, S.W. \& Keraro, F.N. (2005). Effect of concept mapping teaching approach on secondary school students' achievement in Biology in Gucha District, Kenya, Zimbabwe. Journal of Educational Research, 17(1), 1.

Osborne, R. \& Freyberg, P. (1985). Learning in science: The implication of children's science.

Öztürk, A. (2009). Examination of physics problem solving periods of prospective science and technology teachers who have high and low success levels in physics problem solving in terms of cognitive awareness. Master's Thesis, Çukurova University, Institute of Social Sciences, Adana.

Papanastasiou, E. and Zembylas, M. (2002) 'The Effect of Attitudes on Science Achievement: A Study Conducted among High School Pupils in Cyprus', International Review of Education, 48(6), 469-484.

Peacock, M. 2001. 'Match or mismatch? Learning styles and teaching styles in EFL'. International Journal of Applied Linguistics, 11/1: 1-20.

Polly, D. et al. (2013). The association between teachers' beliefs, enacted practices, and student learning in mathematics. The Mathematics Educator, 22 (2), 11-30.

Redish, E. F., Saul, J. M., \& Steinberg, R. N. (1998). Student expectations in introductory physics.American Journal of Physics, 66(3), 212-224.

Reid, N. and Skryabina, E. (2002) 'Attitudes towards Physics', Research in Science \&Technilogical Education, 20(1), 67-81.

Rivard L. P. \& Straw, S. P. (2000). The effect of talk and writing on learning science: An exploratory study. Science Education, 84, 566-593.

Roberts,C. B. (2000). Learning theory.2nd Edition, University of Washington, Rinehart and Winston Ltd. New York.

Samba, R.M.O. (2003). Promoting students' understanding of photosynthesis and respiration: An evaluation of the potency of a conceptual change instructional strategy The Benue Valley: Journal of Inter disciplinary Studies; 2: 100-114.

Schunk, D. H., \& Richardson, K. (2011). Motivation and self-efficacy in mathematics education. In D. J. Brahier \& W. R. Speer (Eds.), Motivation and disposition: Pathway to learning mathematics). Reston, VA: The National Council of Teachers of Mathematics.

Selçuk, G. S., Çalışkan, S., \& Erol, M. (2008). Physics self-efcacy beliefs of student teachers': The relationships with gender and achievement perception. Balkan Physics Letters (Special Issue: Turkish Physical Society 24th International Physics Congress), 648-651.

Semela, T. (2008). Predicaments of female success in higher education in Ethiopia: Impacts of gender role socialization and prior academic preparation. Ethiopian Journal of Development Research, 30(1), 85-132.

Shavelson, R. J., Hubner, J. J., \& Stanton, G. C. (1976). Self-concept: Validation of construct interpretations. Review of Educational Research, 46(3), 407-441.

Shaw, K. A. (2004). The development of a physics self-efcacy instrument for use in the introductory classroom, AIP Conference Proceedings, 720 (1), 137-140.

Stokking, K.M. (2000). Predicting the choice of physics in secondary education. International Journal of Science Education, 22 (12), 1261-1283.

Tanel, R., (2013). Prospective physics teachers' self-efficacy beliefs about teaching and conceptual understandings for the subjects of force and motion. Journal of Baltic Science Education, 12 (1), 6-20.

Tatar, N., \& Buldur, S. (2013). Improving preservice science teachers' self-efficacy about the use of alternative assessment: Implication for theory and practice. Journal of Baltic Science Education, 12 (4), $452-464$.

Tobias, S., \&Birrer, F. A. J. (1999). Who will study Physics and why? European Journal of Physics, 20, 365-371.

Valentine, J. C., Dubois, D. L., \& Cooper, H. (2004). The relation between self-beliefs and academic achievement: A meta-analytic review. Educational Psychologist, 39(2), 111-133.

Vardarl1, G. (2005). Regression of the self-efcacy levels of second grade elementary school students. Master's Thesis, Ege University, Institute of Social Sciences, İzmir.

Velayutham, S., Aldridge, J. M., \& Fraser, B. (2012). Gender differences in student motivation and self-regulation in science learning: a multi-group structural equation modeling analysis. International Journal of Science and Mathematics Education, 10, 1347-1368. 
Velayutham, S., Aldridge, J., \& Fraser, B. (2011). Development and validation of an instrument to measure students" motivation and self-regulation in science learning. International Journal of Science Education, 33(15), 2159-2179.

Veloo, A., Nor, R., \& Khalid, R. (2015).Attitudes towards Physics and Additional Mathematics Achievement towards Physics Achievement. , 8(3), 35 - 43. International Education Studies, 8(3), 35-43.

Wilson, L. V., Ackerman, C., \& Malave, C. (2000). Cross - Time Attitudes, Concept Formation, and Achievement in College Freshman Physics. Journal of Research in Science Teaching, 37(10), 1112-1120

Woo, T. N. (1999). Relationship between self-efcacy in biology and academic achievement and its effects in parallel discussion. Master's Thesis, National Taiwan Normal University.

Woolnough, B.E. (1994) 'Why students choose physics, or reject it', Physics Education, 29 368-374.

Yener, D., Aydın, F., \& Köklü, N. (2012). Examination of students' self-efcacy in physics laboratory in which animation-simulation are applied. 10th National Congress on Science and Mathematics Education. Nigde University, Nigde.

Yip, D. Y. (2001). Promoting the development of a conceptual change model of science instruction in prospective secondary biology teachers. International Journal of Science Education; 23(7): 755-770.

Ziegler, A., Broome, P., \& Heller, K. (1999). Golem und enhancement: elternkognitionen und das schulische Leistungshandeln in Physik [Golem and enhancement: parental cognitions and their children's scholastic achievement behavior patterns in physics]. Zeitschrift für Pädagogische Psychologie, 13(3), 135-147.

Zimmerman, B. J. (2000). Self-efficacy: An essential motive to learn. Contemporary Educational Psychology, $25(1), 82-91$. 